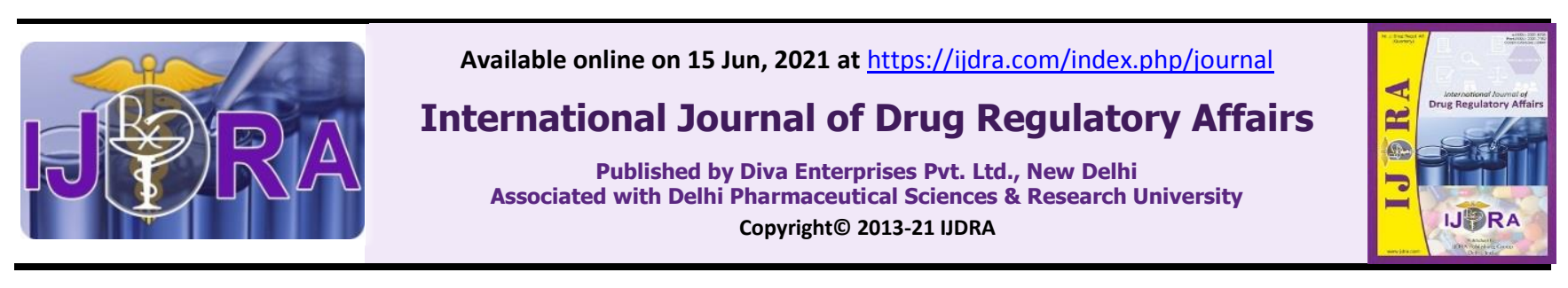

Review Article

\title{
Regulatory procedures for emergency approval of medical products by regulatory agencies
}

\author{
G HariCharan ${ }^{\text {a }}$, Kishore Kumar Ramoju*, ${ }^{*}$, Suhana S ${ }^{\text {c }}$, Yamini Lindait ${ }^{d}$ \\ ${ }^{a}$ Internal Medicine Specialist, CARE Hospitals, Hyderabad, India \\ ${ }^{b}$ Institute of Technology, Carlow, Ireland. \\ ${ }^{c}$ Pharm-D, V Year, Dayanand Sagar University, Bangalore, India \\ ${ }^{d}$ Pharm D, IV Year, Indira college of Pharmacy, Pune, India
}

\begin{abstract}
Emergency use authorization of medical products by the regulatory agencies is not a usual procedure; it happens to cope with unanticipated health emergencies affecting a large group of population, these can be because of outbreak agents like virus, bacteria, etc., which can cause contagious diseases. Contagious diseases are classified into an outbreak, epidemic and pandemic disease, based on size and intensity of spread of the disease. Epidemic and Pandemic disease conditions such as CoVID-19 will trigger the emergency use authorization of products that help in the control, prevention and/or cure for the disease. EMA and FDA are well known advanced regulatory bodies, with eminent procedures for approval of the medication, harmonization of the standards as per the global regulatory acceptance. However, there are some differences between the two, in case of initiating the procedure, timelines, data required for approval of products under the emergency use. This article focuses on emergency approval of medications, regulations involved in the approval of medications and vaccines by EMA and FDA, some of the important data companies or sponsors need to submit to the regulatory bodies for approval, verification procedure and timelines for evaluation of manufacturer submitted data. Mutual recognition agreement and timeline of Remdesivir for approval by EC and FDA.
\end{abstract}

Keywords: Compassionate use, MRA, EMA, FDA, COVID-19, Remidesivir, Emergency use authorization (EUA)

Article Info: Received 28 Apr. 2021; Review Completed 04 Jun. 2021; Accepted 07 Jun. 2021

Cite this article as:

Charan GH, Ramoju KK, Suhana S, Lindait Y. Regulatory procedures for emergency approval of medical products by regulatory agencies. Int J Drug Reg Affairs [Internet]. 2021 Jun 15 [cited 2021 Jun 15]; 9(2):1-5. Available from: http://ijdra.com/index.php/journal/article/view/459

DOI: $10.22270 /$ ijdra.v9i2.459

*Corresponding author

\section{Introduction}

Globalization has not only led to the growth of harmonization in the standards of living among nations, but it has also led to the rapid outbreak of diseases into pandemic statues. Currently, every nation in the world is battling the CoVID-19 pandemic, however there is no clear conspiracy behind the outbreak of this disease. Approximately, it has affected 80 million people and led to the death of nearly 10 million people across the world.

In this time all the pharmaceutical regulatory bodies like FDA, EMA, CDSCO, BfArM etc. are encouraging biotechnology and pharmaceutical companies to develop vaccines or drugs to eliminate the pandemic. In order to decrease the approval timeframe of developed medications, agencies have already started to incipient new-fangled guidelines for approval and release of the drugs into the market, parallely tackling uncertainties. $(1,2)$
While the world is overwhelmed with uncertainties bestowed upon by a pandemic outbreak, agencies will have to strategise a way out, such as; the government will have to work on par with national agencies, nonprofit organizations and pharmaceutical companies to develop a synchronised strategy prioritizing and speeding the development of the most promising vaccines. $(1,2)$

Terminology for approval of drugs or vaccines to counter the emergency has different names in different agencies. FDA approval procedure is called Emergency use authorization (EUA) and in the EU region it is called Conditional use authorization.

\section{Food and Drug Agency (FDA)}

FDA has introduced the Emergency use authorization (EUA) under the Project Bioshield Act of 2004. Peramivir was the first medication to be approved under EUA to fight against H1N1 influenza pandemic in April 
2009. Validity of the EUA is for 1 year, but it can be renewed, based upon the conditions of the emergency. It is important that the EUA approved medical product needs to prove its efficiency and safety during its clinical trials, because EUA is an instant procedure intended to release the product for consumption during an emergency circumstance. (3)

There is a misinterpretation that compassionate use and emergency use authorization is the same, which is not the case. The terms 'Emergency use medications' and 'compassionate use medications' are interchanged

Table 1. Difference between Emergency use and Compassionate use of medication is stated below as reported by US FDA $(3,4)$ :

\begin{tabular}{|c|c|c|}
\hline Parameters & Emergency use & Compassionate use \\
\hline Criteria & $\begin{array}{l}\text { 1) When no alternative is available and when } \\
\text { there is no time to get approval from the } \\
\text { agency. } \\
\text { 2) In serious life-threatening conditions or } \\
\text { serious disease conditions. }\end{array}$ & $\begin{array}{l}\text { 1) When no alternative medication } \\
\text { is available. } \\
\text { 2) Serious health condition. }\end{array}$ \\
\hline Usage population & Used in limited patients. & $\begin{array}{l}\text { Used by an individual or a small } \\
\text { group of population. }\end{array}$ \\
\hline Time of usage of medication & $\begin{array}{l}\text { Can be used before or after the start of a } \\
\text { clinical trial. }\end{array}$ & Used only during clinical trials. \\
\hline Prior approval & Not required & Required \\
\hline
\end{tabular}

\section{Process of EUA by FDA}

Determination of military emergency or significant potential for military emergency or determination of domestic emergency or significant potential for domestic emergency or determination of public health emergency or significant potential for public health emergency or identification for material threat after the determination by these four agencies, secretary of HHS issues an EUA declaration after approaching assistant secretary for preparedness and response, the director of the national institutes of health (NIH) and the director of CDC.

Under the section 564(b)(1) of the Federal Food, Drug, and Cosmetic Act, when the HHS secretary declares that an EUA is appropriate. (5)

\section{Data requirements for $\mathbf{E U A}$}

Sponsors need to submit any statistical analysis of the data which proves safety and effectiveness along with the interim reports that are available with a clear viewpoint on the product.

The lab data of the animal and human studies need to be submitted along with the information about the adverse events irrespective of the casualty. Case report forms of individuals that died during their participation in the clinical trial need to be submitted. The literature of the submitting documents needs to be in English language. Sponsors need to submit the documents that the labs reports follow good laboratory practice for nonclinical laboratory studies regulations.

Sponsors need to submit the data about the risk and benefits of the product along with measures taken to mitigate risk, limitations, uncertainty and data gaps, contra indicatory situations. (5)

\section{Import or export of medications}

sometimes which is incorrect, because emergency use medications are those medications which are meant to be used in emergency conditions and the authorization to sell in market are done without the requirement of clinical trials of these medications. Compassionate use medications are those which are used outside of clinical trials to diagnose, monitor, or treat patients with serious disease or in conditions which do not have comparable or satisfactory approved therapy options available. (4)
When the drug is produced in countries other than the USA or manufactured in the US to export or import the medications, then in such conditions the counter measures can be drawn as per section 801 of the FD\&C Act. The letter of authorization will serve as a certificate that the drug is legally imported or exported.

\section{Termination and renewal of the EUA}

The HHS secretary will terminate on prior when the HHS secretary determines the circumstances that precipitated the declaration have ceased or a change in the approval status of the product such that authorized use of the product are no longer unapproved, renewals are made by the HHS secretary in accordance with the section 319(a)(2) of the Public Health Service Act 42 U.S.C $247 d(a)(2) .(5,6)$

\section{COVID-19 Vaccine approval under EUA by FDA}

Regarding the CoVID-19 pandemic FDA has requisitioned the sponsors and other bodies to produce vaccines in order to counter the unforeseen emergency. Manufacturers need to submit clinical and non-clinical data with proven patient safety and efficiency of the product that intends to be effective against CoVID-19. In Phase I clinical trials, a vaccine is given to healthy volunteers to determine the safety and identify human immune response to the medication. In Phase II clinical trials, vaccine is administered to hundreds of subjects in a randomized and controlled manner and in this phase common side effects, immune response, and effectiveness of vaccine are observed. In phase 3 clinical trials, vaccines will be administered to a larger population, in this phase immune response to vaccine is compared with those who receive a control (Placebo).

To find safety and effectiveness of the vaccine subjects that were a part of phase III trials will be under 
supervision for at least a month post vaccine regimen in order to track serious adverse events, if any. $(6,7)$

Even after receiving the approval from EUA, the FDA will expect the sponsor to perform clinical trials and update the safety and efficiency of the product in the market. Data safety Monitoring board will help in assessing the safety of the product and there are some bodies such as Vaccine adverse event reporting system (VAERS), the vaccine safety datalink (VSD), Biologics effectiveness and safety (BEST) and Medicare claims data that help FDA in rapidly determining the safety of the product. (7)

\section{European Commission}

In European union authorization, the process of using medical products to battle uncertainties is termed as conditional marketing authorisation.

Conditional marketing authorization is defined as the approval of a medicine that addresses unmet medical needs of patients based on less comprehensive data than normally required. The available data must indicate that the medicine's benefits outweigh its risks, and the supplicant should be able to provide the comprehensive clinical data in the future.

Sutent was the first medicinal product to be approved under the conditional marketing authorization on 19 July 2006 by the European Commission.

Medicinal products can be considered for conditional marketing authorization as per the Article 2 of Regulation no. 507/2006 based on the following scope:

- Medicinal products that intend to treat or prevent or diagnose serious medical circumstances or lifethreatening ailments.

- In conditions where World Health Organisation or situations as per the 2119/98/EC framework have detected emergency situations with regards to the public health.

- Products that are considered as orphan medicinal products in accordance with the Article 3 of regulation (EC) No. 141/2000.

Requirements to grant permission for condition marketing authorization -

There are 4 conditions as per the Article 4(1) of Regulation no 507/2006:

- Unmet medical conditions in the society.

- Should benefit the public on immediate availability in the market.

- Risk-benefit balance of the medicinal product.

- The applicant is in a condition to provide the clinical data.

Legal bases for the approval of the conditional marketing authorization of the product into the market must follow the regulations laid in the Article 11 of the commission regulation (EC) No. 507/2006 and Regulation No. 726/2004. $(8,9)$

\section{Process of application}

Either the applicant or CHMP needs to notify the EMA about conditional marketing authorization of the product. Applicants need to submit a letter of intent to EMA and also a request letter needs to be presented in the module 1.5.5 of EU-CTD.

Applicants need to provide a justification of how the product falls under the scope of conditional marketing authorization and its requirements as per the Article 2 and Article 4 of Regulation no. 507/2006 as mentioned above.

The Applicant with a potential conditional marketing authorization can request the CHMP in assisting the protocol or to render scientific advice. $(9,10)$

\section{Renewal of Conditional marketing authorization}

As per Article 6 of commission regulation 507/2006, Conditional marketing authorization is valid for duration of one year, post which the applicant needs to renew it. To renew the conditional marketing authorization, the applicant needs to submit a renewal application six months prior to the expiry of application with an interim report. Applicants need to address all the special obligations mentioned in the renewal application form. (10)

\section{Vaccine approval under Conditional marketing authorization}

EMA will recommend approval of the vaccine under the condition only if the applicant is able to prove that the vaccine possesses high standards in terms of quality, safety, and efficacy. Applicants need to conduct the studies involving pharmaceutical quality studies, nonclinical studies, and clinical studies. Pharmaceutical quality studies such as shelf life, stability, purity of components and storage conditions need to be performed within certified facilities. Immunogenicity, animalchallenge and biodistribution studies need to be performed under non-clinical studies. Clinical studies look into the immune responses, efficacy and safety studies. Evaluation of a medicine by EMA will take 210 active days, however; in response to the current uncertain conditions, CoVID-19 products are treated in an expedited manner which allows the evaluation period to be less than 150 working days. Also, EMA opts for a rolling review of the products, which means assessing data will be done once they become approved during the development process. $(11,12)$

\section{Mutual Recognition Agreement (MRA)}

Since the start of the 20th century most of the regulatory agencies are striving for harmonization of regulation or a procedure which eases the approval of medication and makes it available to the people in need, consequently a Mutual Recognition Agreement between the agencies was proposed to serve the purpose. MRA will help in reducing the technical barrier, exchange of information, declarations of conformity, acceptance of the certificates, reports and authorizations. In European commission of European Union and FDA, the transition phase for human use medicines was completed on 11 July 2019. Prior to the agreement, both the agencies had 
inspected each other's GMP facilities and confirmed that the facilities were in line with their own guidelines. Products covered in this agreement are tablets, ointments, injections, medical gases, herbal products, homeopathic products, allergenic products, and bulk drug substances. Products that were excluded are human tissues, organs, blood, plasma and advanced therapy medicinal products. Decisions about the vaccines for human use are to be expected by 15 July 2022. (13)

\section{Remidesivir approval in emergency conditions by EMA and FDA}

Remidesivir is a medicine that was approved for compassionate use to treat people who are tested positive for CoVid-19 in March 2020 by FDA. In the month of April 2020, EMA had provided recommendations for compassionate use of Remdesivir for COVID-19 in the EU to EC. In April 2020, FDA approved EUA for Remidesiver based on the study "Adaptive COVID-19 Treatment Trial 2 (ACTT-2)", a study conducted by National Institute of Allergy and Infectious Diseases (NIAID). In April 2020 EMA started rolling reviews based on ACTT study and provided Conditional marketing authorization because of MRA between FDA and EC. $(14,15)$

\section{Conclusion}

Approval of a product with minimal data submitted by the applicant in desperate times and counting on it to fight against the odds is taxing for regulatory bodies. As mentioned earlier, submission of the data to regulatory bodies is very vital and it has to be meticulous as per the guidelines. Advisory bodies do not only assist agencies in the approval process of the vaccines and/or drugs in emergency conditions, but they also aid in development of robust regulatory guidelines for the procedure, termination, import and export of the medications meant to treat emergency conditions. Harmonization between the agencies matters a lot while battling uncertainties, however there is a mutual recognition agreement (MRA) between EC and FDA for drugs but there is no such agreement for vaccines between the two agencies, although, both the agencies are trying to achieve it till date. MRA is a promise to slacken the evaluation process of applications submitted by the applicants who have the potential drugs or vaccines to fight against an emergency or to treat an unmet medical condition.

\section{Acknowledgements}

We would like to express our sincere gratitude to IJDRA Journal for publishing our article.

Financial Disclosure statement: The author received no specific funding for this work.

\section{Conflict of Interest}

The authors declare that there is no conflict of interest regarding the publication of this article.

\section{References}

1. Thomson K, Nachlis H. Emergency Use Authorizations During the COVID-19 Pandemic: Lessons From Hydroxychloroquine for Vaccine Authorization and
Approval. JAMA [Internet]. Pubmed; 2020 Oct 6 [cited on 2021 Mar 15]; 324(13):1282-1283. Available on:

https://pubmed.ncbi.nlm.nih.gov/32870235/

2. SC, Supriya Kumar, Freimuth V S, Kidwell K., and Musa D. "Public willingness to take a vaccine or drug under Emergency Use Authorization during the 2009 H1N1 pandemic." Biosecurity and bioterrorism: biodefense strategy, practice, and science [Internet] ncbi; 2009 [cited on 2021 Mar 06]; 7(3):275-290. Available at:

https://www.ncbi.nlm.nih.gov/pmc/articles/PMC2998968/

3. U.S. Food and Drug Administration. 2021. FDA Issues Emergency Use Authorization for Third COVID-19 Vaccine [Internet]. FDA; 2021Feb 27 [cited on $2021 \mathrm{Mar}$ 05] Available at:

https://www.fda.gov/news-events/press-

announcements/fda-issues-emergency-use-authorizationthird-covid-19-

vaccine\#: :text=Today $\% 2$ C $\% 20$ the $\% 20$ U.S. $\% 20$ Food $\% 2$ 0and,SARS\%2DCoV\%2D2).

4. Tsuyuki K, Yano K, Watanabe N, Aruga A, Yamato M. Compassionate use of drugs and medical devices in the United States, the European Union and Japan. Regenerative Therapy [Internet]. Ncbi; 2016 Jun 01 [cited on 2021 Feb 21]; 4:18-26. Available at:

https://www.ncbi.nlm.nih.gov/pmc/articles/PMC6581800/

5. U.S. Food and Drug Administration. GuidanceEmergency Use Authorization of Medical Products [Internet]. FDA; July 2007. [Cited on 2021 Mar 20] Available at:

www.fda.gov/RegulatoryInformation/Guidances/ucm1251 27.htm. .

6. Emergency Use Authorization Declaration [Internet]. Federal Register; 2020 [cited Mar 15 2021]. Available from:

https://www.federalregister.gov/documents/2020/03/27/20 20-06541/emergency-use-authorization-declaration.

7. Nightingale SL, Prasher JM, Simonson S. Emergency Use Authorization (EUA) to Enable Use of Needed Products in Civilian and Military Emergencies, United States. Emerg Infect Dis. 2007;13(7):1046.

https://doi.org/10.3201/eid1307.061188

8. European Medicines Agency. Conditional marketing authorisation [Internet]. European Medicines Agency [cited 2021 Mar 20]. Available from:

https://www.ema.europa.eu/en/humanregulatory/marketing-authorisation/conditionalmarketing-authorisation

9. Avorn J, Kesselheim A. Regulatory decision-making on COVID-19 vaccines during a public health emergency. Jama [Internet]. Pubmed; 2020 Oct 06 [cited on: 2021 Jan 25];324(13):1284-5. Available on :

https://pubmed.ncbi.nlm.nih.gov/32870268/

10. European Medicines Agency. Guideline on the Scientific Application and the Practical Arrangements Necessary to Implement Commission Regulation (EC) No 507/2006 on the Conditional Marketing Authorisation for Medicinal Products for Human Use Falling Within the Scope of Regulation (EC) No 726/2004 [Internet]. European Medicines Agency; 2016 Feb 25 [cited on 2021 Mar 15] Available on:

https://www.ema.europa.eu/en/documents/scientificguideline/guideline-scientific-application-practicalarrangements-necessary-implement-commissionregulation-ec/2006-conditional-marketing-authorisationmedicinal-products-human-use-falling_en.pdf

11. Cavaleri M, Enzmann H, Straus S, Cooke E. The European Medicines Agency's EU conditional marketing authorisations for COVID-19 vaccines. The Lancet [Internet]. Ncbi; 2021 Jan 30 [cited on 2021 Mar 26];397(10272):355-7. Available on: 
https://www.ncbi.nlm.nih.gov/pmc/articles/PMC7833511/

12. COVID-19 guidance: evaluation and marketing authorisation - European Medicines Agency [Internet]. European Medicines Agency; 2021 [cited 21 March 2021]. Available from:

https://www.ema.europa.eu/en/human-

regulatory/overview/public-health-threats/coronavirus-

disease-covid-19/guidance-developers-companies/covid19-guidance-evaluation-marketing-authorisation.

13. Mutual recognition agreements (MRA) - European Medicines Agency [Internet]. European Medicines Agency; 2021 [cited 22 March 2021]. Available from: https://www.ema.europa.eu/en/humanregulatory/research-development/compliance/goodmanufacturing-practice/mutual-recognition-agreementsmral

14. Lamb Y N. Remdesivir: first approval. Drugs [Internet]. Pubmed; 2020 Sep 01 [cited on 2021 Mar 19]:1-9. Available on: https://pubmed.ncbi.nlm.nih.gov/32870481/

15. Saint-Raymond A, Sato J, Kishioka Y, Teixeira T, Hasslboeck C, Kweder SL. Remdesivir emergency approvals: a comparison of the US, Japanese, and EU systems. Expert Review of Clinical Pharmacology [Internet] 2020 Oct 2 [Cited on 2021 Mar 05];13(10):1095-101. Available on: https://www.tandfonline.com/doi/full/10.1080/17512433. 2020.1821650 